\title{
UNIVERSAL, SINGULAR E EXCLUÍDO: A CONSTRUÇÃO DO LUGAR DO ADOLESCENTE POBRE NA SOCIEDADE BRASILEIRA
}

\author{
Marilúcia Pereira do lago \\ Universidade Federal de Goiás (UFG), Goiânia, Goiás, Brasil \\ Geisa Nunes de SOUZa Mozzer \\ Universidade Federal de Goiás (UFG), Goiânia, Goiás, Brasil \\ DIANE VALDEZ \\ Universidade Federal de Goiás (UFG), Goiânia, Goiás, Brasil
}

RESUMO: O artigo propõe uma reflexão sobre o lugar coletivamente construído e destinado a adolescentes pobres na sociedade brasileira, por meio da história de políticas e práticas da educação para meninos e meninas do Brasil, desde a colonização portuguesa ao Estatuto da Criança e do Adolescente. O texto retoma o conceito de situação social do desenvolvimento a fim de perceber que o sujeito não é separado da sua história e o seu desenvolvimento está entrelaçado as suas condições de vida, suas relações sociais e seu universo simbólico. Produto e produtor de história, o homem carrega os traços do seu lugar na sociedade e fala a partir deste lugar. Por isso mesmo, não se pode pretender compreender o comportamento do adolescente em conflito com a lei ou pretender educá-lo, sem a compreensão de que, historicamente, ele fala de um lugar social de exclusão e violência.

Palavras-chave: Adolescente pobre. Exclusão social. Lugar da educação. 
INTRODUÇÃO

Vez que nomeamos cada fase do ciclo da vida, todos os homens passam pela experiência da adolescência, tanto quanto da infância e da velhice. Isso aponta para o universal ético que baliza os direitos posto que, reconhece em todo e qualquer homem, necessidades e direitos comuns em cada etapa do desenvolvimento. Adolescência é assim, um conceito universalizado para designar a experiência do crescimento rumo à vida adulta. No entanto, se considerarmos que existem vários mundos dentro do Mundo, várias realidades e contextos sociais e culturais, diremos que a cada sol, uma adolescência. Falemos então, de Adolescências. São realidades e experiências plurais e, como cada homem cresce singularmente e de acordo com o cenário no qual está inserido e participa, a singularidade se constrói nesse plural.

Este texto debruça sobre uma dessas realidades, vamos tratar de um mundo, um lugar para a experiência do adolescer no Brasil e de uma experiência singular no desenvolvimento, o adolescente infrator. Porque o irônico por vezes se faz necessário, é importante dizer que não se trata do estudo de uma síndrome. Por mais que tentou, a ciência ainda não pode comprovar a existência de uma anomalia genética que pudesse determinar que tal criança, ao chegar à fase de desenvolvimento conhecida como adolescência, estaria sujeito a cometer atos infracionais. Também não estamos falando de uma etnia presente na realidade brasileira. Poderíamos sim, falar de comportamento humano e então, a "delinquência" poderia ser analisada a partir de diversos fatores, sociais, culturais, psicológicos e outros, muito bem estudado por diversos autores.

A nossa reflexão aponta para a compreensão de lugar construído, ou seja, o entendimento de que, dentro da pluralidade de contextos e realidades no Brasil, existe um lugar, construído coletivamente e ao longo da história, para o desenvolvimento do adolescente infrator. Trata-se de um espaço de exclusão, perfeitamente paramentado de políticas e instituições de manutenção da exclusão que obedece a uma compreensão estreita e historicamente desigual de sociedade, mas que, absurdamente, acaba por ser entendido como status quo. Por isso, é importante revisitarmos a história e buscar compreender de que forma esse lugar foi construído e destinado para experiência de parte da população brasileira. E a história é tão longa quanto é a nossa responsabilidade coletiva. Selecionamos para nossa reflexão o espaço de construção que vai do Brasil de colonização portuguesa até a promulgação do Estatuto da Criança e do Adolescente em 1991. 
A história é complexa e os sentidos dados a adolescência e seus espaços educativos se diferenciam, transformando de acordo com as mudanças exigidas no tempo e no espaço. Pensar em um passado plural, não homogêneo e não linear, é cingir essas diferenças evitando admitir uma única prática, imposta como absoluta ou como superior. Da mesma forma que não há continuidade regular na história, começo, meio e fim, não é possível retirar do cenário as tensões, conflitos, contradições especificidades de cada tempo histórico. Ao simplificar, reduzir, impor e cobrar práticas atuais do passado cai-se no risco de cometer anacronismo, que é olhar para o passado com olhar do presente, onde tudo beira o caos, a desordem e a ausência. Por isso, consideramos relevante abordar um pouco da relação passado-presente para visualizar a trajetória dos lugares reservados aos meninos e meninas na história, observando as transformações e as permanências'.

LUGARES DE EDUCAR: MENINOS E MENINAS POBRES NA HISTÓRIA BRASILEIRA

Ao falarmos de "lugares de educar", estamos ampliando o conceito de educação, que aqui não se limita ao aspecto escolar em formato de instituições. Na História social, os lugares de educação adquirem contornos diversos, podendo se dar no interior da família, grupos, trabalho, espaços privados, públicos, religiosos, laicos e outros. Seguindo esta perspectiva, adotamos o uso de "meninos e meninas" ao invés de adolescentes, pois esse termo não responde por um passado mais distante e não é possível cobrar de outros tempos conceitos, práticas e ações que vigoram no presente. A concepção sustentada pelo Estatuto da Criança e do Adolescente (ECA) entende que a criança e o adolescente, bem como as suas respectivas famílias, devem estar assegurados por políticas públicas de proteção e promoção de direitos. O ECA também define a idade do que se considera criança e adolescente, assim como as especificidades das políticas para cada um². Contudo, a idade cronológica, tanto da infância, como da adolescência, sempre foi flutuante na história, as faixas etárias, encontradas nos documentos da América portuguesa, Brasil Imperial e Republicano, evidenciam que não era a idade o único critério para definir esta fase, as diferenças culturais e sociais interferem na construção simbólica de vocabulários específicos ${ }^{3}$.

Ao pensarmos os espaços educativos para esse público em tempos históricos e nos espaços geográficos temos uma infinidade de chaves que não são do mesmo tamanho ${ }^{4}$, da mesma forma que classificações das etapas de vida não têm o mesmo sentido. Falar de maioridade, maturidade, carência de 
discernimento, inexperiência, imprudência, nem sempre se adéquam automaticamente ao que configura o adolescente, menino, jovem, mancebo, moço, rapaz, moleque, moçoilo, núbil, frangote, rapazinho, homem jovem, garoto, guri, rapazote, miúdo, curumim etc. Por outro lado, definições pejorativas impostas socialmente como: menor, delinquente, carente, vadio, gatuno, pivete, arruaceiro, perigoso, desvalido, infeliz da sorte, desprotegido, deserdado, abandonado, desamparado, miserável, pobre, enjeitado, insignificante e outros, provém de práticas historicamente construídas que nem sempre são fáceis de serem analisadas.

De forma bastante resumida, daremos pistas de algumas políticas, ou práticas, voltadas para esse público, nos espaços educativos impostos a ele. Como não é possível fazer um estudo amplo, optamos por contemplar os lugares destinados aos meninos e meninas pobres no Brasil de colonização portuguesa (1500-1822), em seguida no Império brasileiro (1822-1889) e na República, priorizando o período que vai até os anos 80 .

\section{Pelos mares e pelas "Novas terRas": \\ OS ESPAÇOS DE FORMAÇÃO DE MENINOS E MENINAS}

No cenário da colonização portuguesa em terras brasileiras não há como desconsiderar a presença de meninos e meninas que viviam e cresciam sob diferentes normas de educação. Certamente esse período nos remete à educação imposta aos filhos dos indígenas (legítimos donos da terra), assim como aos filhos dos escravos africanos, trazidos à força para servirem de mão de obra nas terras portuguesas. Contudo, vale observar a presença de outros meninos e meninas, em idade que hoje consideraríamos adolescentes, que integravam o processo de colonização, seja no interior das embarcações marítimas como nas terras brasilis. Compunham a tripulação das embarcações os grumetes, os pajens e as órfãs del rey, que a despeito das diferenças de papéis, tinham em comum as idades que variavam entre dez a 18 anos, a condição social e a não possibilidade de escolha. Os grumetes, meninos recrutados nas famílias portuguesas pobres, supriam a falta de mão de obra das embarcações, eram responsáveis pela limpeza, manutenção das velas, preparo de comida e outros serviços de gente adulta. Desempenhando o papel de serviçais, os pajens, contratados pela coroa, realizavam trabalhos mais leves, como servir os nobres lusitanos e dar conforto aos oficiais. Já as órfãs del rey eram meninas recrutadas para migrarem para o Brasil com o propósito de se casarem com os colonos e formarem família 5 . Nas viagens, 
esses ficavam expostos não somente aos perigos próprios, como naufrágios, piratas, epidemias, tempestades e outros, como também aos maus tratos e abusos sexuais por parte da população adulta, marujos, marinheiros, oficiais etc. Em terra firme, seguiam submetendo-se as imposições dos adultos, sem suas famílias, sobreviviam à própria sorte, não encontrando nem a proteção da igreja, que se ocupava da educação religiosa dos filhos dos indígenas e dos filhos dos colonos ricos nos colégios.

A educação dos curumin $s^{6}$ fazia-se distante das restrições impostas aos meninos e meninas europeus. Esses cresciam nas matas aprendendo com a experiência dos adultos, não sofriam castigos, maus tratos e, de acordo com a sua comunidade, passavam por rituais que definiam a entrada para $o$ mundo adulto. Os diferentes rituais na puberdade marcavam a iniciação tanto para a constituição familiar, como para se iniciar no mundo de guerreiro. A idade cronológica não demarcava a passagem da infância para adolescência, pois diferente da população não indígena, não era o tempo que definia os rituais e sim a natureza do menino ou menina, que poderia se manifestar em diferentes tempos. A educação que recebiam em suas comunidades, nem de longe lembrava a ministrada pelos padres jesuítas nas missões que, diante da tentativa frustrada de converter os indígenas adultos, investiram fortemente na educação das crianças, consideradas papéis em branco onde poderiam determinar os princípios necessários para a conversão. Ainda que essa imposição não alcançasse sempre bons resultados, os padres não encontravam grandes resistências com a pequenada que recebia as primeiras instruções (ler, escrever e contar), e pela sujeição e temor, era formada para se afeiçoar à nova cristandade, o que transformava radicalmente a vida dela ${ }^{7}$.

Não obstante ao relativo sucesso com os pequenos, os padres enfrentavam problemas ${ }^{8}$, sobretudo com os meninos que antes se entregavam aos divinos ensinamentos cristãos e quando chegavam aos anos da puberdade, corrompiam-se e, segundo as cartas dos padres, desavergonhados, bebiam, cometiam luxúria, pecados da carne, andavam nus etc. Os "moços" trocavam a obediência pela ingratidão, tornando-se pessoas perigosas. Portanto, a idade superior aos 12 anos marcava a expulsão do paraíso prometido pelo clero jesuítico?.

Em relação à educação dos meninos e meninas africanos, chamados de moleques e molecas, Goes e Florentino (1999) ressaltaram alguns ritos que marcavam a passagem da infância para a adolescência na África. Em algum lugar desse grande continente, na primeira menstruação, a menina, reclusa, seria proibida de comer alguns alimentos, em outro lugar, o corpo 
marcaria a nova condição com a extração do clitóris e retirada do hímen, em outro, evitaria contato com homens e gados e, os mais velhos, invocariam ancestrais, sacrificariam bichos e outros rituais marcariam esta passagem, tanto de meninas como de meninos.

No Brasil, no lugar de se exaltar a fertilidade, procriação, coragem etc., o ingresso desses ao mundo dos adultos se dava por outras passagens, em especial pelo adestramento e obediência ao mundo do trabalho. A primeira formação de trabalho se dava no interior das Casas Grandes, como serviçal, moleque de recados, carregadores, pajens etc. Por volta dos 10 ou 12 anos, o destino da educação dos meninos e meninas já estava determinado pelo sobrenome que indicava seu trabalho, como por exemplo, "Chico Roça" ou "Ana Mucama". A idade ocidental designava as ocupações destes meninos e meninas, que, matriculados por imposição na degradante escola da escravatura, desempenhavam tarefas de adultos, onde a repressão, a mesma dada aos seus familiares, lançava o trabalho como opção única.

Além do que foi ressaltado, vale notar que neste período histórico, havia instituições complexas de ensino, vigilância e enquadramento deste público, como os colégios, casas de meninos, seminários e internatos de cunho religioso. Além destes espaços, havia as escolas domésticas não religiosas sem vínculo com o Reino e, para os mais abastados, a educação dada pelas preceptoras e preceptores estrangeiros. Espaços que privilegiavam o ensino secundário, responsável por prepará-los para ingressar no ensino superior, contudo, para meninos e meninas pobres, impunham uma educação baseada na condição social, gênero e etnia.

\section{A EDUCAÇÃO DOS FILHOS DE "MÁ SORTE" NO IMPÉRIO BRASILEIRO}

O período oitocentista que marca o Império brasileiro é considerado o século da instrução. Nesse período, a legislação autoriza o ensino de primeiras letras, ensino secundário e faculdades para a população brasileira. Contudo, essa mesma legislação só proporcionava o acesso à escola primária para crianças livres, sadias e vacinadas, ou seja, os filhos dos escravos estavam fora do processo escolar, juntamente com outros que não moravam nos limites impostos para se criar escolas formais. Vale lembrar que o acesso ao ensino secundário, destinado ao público de faixa etária acima de dez anos, era ainda mais limitado, pois à exceção dos Liceus e Escolas Normais, que eram estabelecimentos públicos, grande parte desta modalidade estava nas mãos da iniciativa particular. Se a meninada pobre não estava nas escolas formais 
restava-Ihes um lugar nas instituições religiosas. Pioneiras no atendimento de meninos e meninas pobres, as casas de Misericórdias, com proposta pedagógica baseada na caridade, intervinham na miséria associando-a aos vícios de ordem moral, abrigando meninos e meninas pobres, em asilos, casas de recuperação, casas de órfãos e outros com o objetivo de formá-los moralmente para o trabalho. Apesar de não ser o objetivo dessas instituições, algumas delas proporcionavam aos internos os rudimentos da leitura e da escrita. A permanência nestes espaços, em geral, finalizava quando esses entravam para a chamada idade de rapaz, que poderia variar, mas se dava em geral por volta dos dez anos, a partir daí, deveriam servir ou famílias ricas, no caso das meninas, ou ao Estado, no caso dos meninos ${ }^{10}$. A partir da segunda metade do século XIX, a prática assistencial começa a estabelecer parcerias com o governo, isso marca, lentamente, mas não definitivamente, a substituição do religioso pelo Estado.

O governo imperial criou formas de atendimento aos filhos da "má-sorte" e, nesse processo que não se deu de forma linear, homogênea e tampouco acelerada, os projetos para "proteger" a infância e a juventude masculina eram, em sua maioria, provenientes da pedagogia militar. As Companhias de Aprendizes Militares, criadas em todo o Brasil, recebiam filhos de pobres, expostos, órfãos, além dos meninos ditos incorrigíveis e problemáticos que eram diretamente encaminhados por seus pais ou tutores, com a esperança de se recuperarem diante da rígida disciplina. Diante da dura rotina de revista, marchas, aulas, oficinas, rezas e, sobretudo, de punições, à menor falta cometida, esta educação objetivava aproveitar os meninos que completavam quatorze anos para o serviço militar, devido a falta de homens para compor o pálido exército imperial. Assim, não seria necessário recrutar outros para servirem o exército, como também, a marinha" ${ }^{11}$. No final do século XIX, exaltando a dicotomia no campo e cidade, as Colônias Agrícolas Orfanológicas, instituições sustentadas pelo higienismo, retiravam meninos e meninas abandonados à "própria sorte" dos centros das cidades para inseri-los sob sistema de internato (total controle), no trabalho agrícola $^{12}$. Considerada eficaz, sobretudo por fazer a correção dos menores abandonados distante das cidades, este tipo de instituição foi largamente aprovada pela sociedade em geral.

Em relação aos filhos dos indígenas, além da catequização, o Estado investiu nos filhos dos "selvagens". Devido à necessidade de apaziguá-los por meio dos aldeamentos ou presídios, mantidos pelo Império, com um tipo de proposta semelhante a que já foi salientada: uma educação baseada na 
organização militar. Além de ensinar a língua portuguesa, doutrina cristã, ler, escrever e contar, para inseri-los na "civilização", os estabelecimentos ensinariam ofícios como carpinteiro, ferreiro e cuidados com a lavoura e pecuária. Depois de devidamente civilizados e treinados, os meninos gentios seriam mão de obra aproveitáveis na economia. Essa confinação, que já não se adequava para os meninos urbanos, obteve menos sucesso com os meninos indígenas que se rebelavam contra os maus tratos a que estavam submetidos pela educação totalmente alheia ao seu mundo, e fugiam em massa. Muitas dessas instituições, a despeito de não serem religiosas, mantinham padres na direção dos estabelecimentos, mas com gastos dispendiosos, essas instituições fracassaram em sua missão de "civilizar" os filhos dos indígenas e muitas fecharam nos primeiros anos.

Em fins do século XIX, o trabalho era a solução para enfrentar a vadiagem que tinha a rua como cenário e para esvaziar asilos que recolhiam a meninada pobre. Além das práticas que já foram citadas, esses também eram enviados para artesões, mestres que exerciam o papel de ensinar os chamados aprendizes, profissões como ferreiro, sapateiro, marceneiro e outros. Apesar de a maioria exercer algum ofício, os meninos que ocupavam as ruas eram vistos com desprezo pelos bem-nascidos, não somente pela cor da pele (filhos de ex-escravos) ou pela condição de pobreza, como também, por serem ainda meninos, que alternavam as obrigações com as aventuras que este espaço oferecia. A intervenção dos leigos na filantropia para conter esse avanço perigoso iniciou-se na segunda metade do século XIX, tomando fôlego na República. Setores dominantes em formato de clubes, associações, damas da caridade, em um esforço sistemático para atenuar o conflito social, adquiriram papel importante.

Pela ação filantrópica, as elites da época empreenderam, juntamente com atendimento direto aos meninos e meninas pobres, diferentes tipos de campanhas morais contra a miséria, campanhas contra alcoolismo, oferecendo assistência de caráter tanto facultativo como condicional. Em trocas dos favores concedidos esperava-se a submissão do beneficiário e mudanças de condutas de acordo com as expectativas da classe dominante. Por meio das fontes, sobretudo, matérias de jornais, é nítida a situação de pobreza em que viviam os meninos aprendizes, vendedores, jornaleiros e outros. Também é notório o incômodo que esses causavam na sociedade urbana, pois a presença dos já chamados de menores, em diversos pontos das cidades, frustrava a tentativa de civilizar a paisagem urbana. Por isso, a decisão e prática, que se estende ao largo da história, numa clara política de separação de 
classes, é a de combater e acabar com a presença dos "delinquentes", retirar os "menores" das ruas e confiná-los no interior dos reformatórios, colônias, asilos, orfanato, serviço militar etc.

As LUZES REPUbLICANAS SOB OS "GATUNOS": REPRESSÃO E CONFINAÇÃO

O final do século XIX foi marcado por mudanças significativas de ordem social, política e econômica. A implantação da República, sob a égide do lema positivista que invocava a ordem e o progresso, estruturava, lentamente, a ordem social que priorizava o trabalho desprezando e hostilizando as classes populares e combatendo toda espécie do que classificavam como vadiagem e outros movimentos provocados por meninos, imigrantes, sindicalistas etc. Oficializava-se o combate a tudo que não se enquadrava na lógica do mercado da industrialização que se impunha, infligindo a repressão em especial aos chamados "menores", meninos e meninas, filhos de ex-escravos, de imigrantes, da área rural e de outros segmentos da pobreza ${ }^{13}$. De acordo com os boletins policiais, os adultos eram responsáveis pelo maior índice (quase totalidade), de homicídios, enquanto que os menores cometiam crimes de desordem, embriaguez, furto ou roubo, gatunagem, e outros. Contudo, para retirar os meninos das ruas, bastavam esses permanecerem nelas, seja perambulando, fazendo travessuras, brincadeiras, lutas, esmolando, fazendo biscates etc. De forma ambígua, a criança e o adolescente, apresentados como o alicerce da formação republicana moderna baseada em princípios morais cívicos e não mais religiosos, tornaram-se a base de preocupação ${ }^{14}$.

Contraditoriamente, a legislação endurece para esse segmento da sociedade. Substituem-se as casas de correção por instituições de caráter industrial, realçando a pedagogia do trabalho para regenerar os que não se enquadravam no regime produtor vigente, prática eficaz e rentável ao mesmo tempo ${ }^{15}$. Como a ação era insuficiente, o Estado criou locais para recolhimento e correção dos jovens delinquentes onde, novamente, o trabalho agrícola em institutos disciplinares é visto como solução. O programa do ensino elementar nesses espaços substituía os princípios cristãos pelos princípios republicanos, investia-se no civismo, hábitos de produção e disciplina militar (soldados para a pátria) ${ }^{16}$. Neste princípio de século, os chamados menores ${ }^{17}$ passaram a ser objetos de atenção, de estudos e de diagnósticos de juristas, médicos, biólogos, psicólogos, antropólogos e educadores, que definiam o melhor tratamento para estes seres desviantes. Em nome da ciência, busca-se compreender cientificamente "as doenças" que provocavam o crime, assim 
como as causas mentais da criminalidade no Brasil, dispositivos da higienização na educação, na primeira metade do século XX. Colocava a criança e o adolescente como objeto de intervenção disciplinar e, dando continuidade ao processo de higienização iniciado em meados do século XIX, amplia-se a intervenção em meninos e meninas pobres pela via do discurso, material e ideológico, higienista, que se impunha como prevenção na família, nas escolas e nas ruas. Nesses espaços, os discursos inspiravam a regeneração de futuros criminosos que necessitavam de um local que os segregassem com medidas higienizadoras, comida, limpeza, disciplina e trabalho.

A reabilitação dos portadores de anomalias se fazia sob forma de reclusão, precaução que não estava isolada de iniciativas que faziam parte de um movimento internacional ${ }^{18}$. Neste período, os meninos e meninas pobres eram ainda mais renegados a uma espécie de limbo e transformados em menores. Só eram reconhecidos como crianças e adolescentes os que pertenciam a uma classe que não fosse marginalizada, que não portassem desvios e que não fossem institucionalizados. O Código de Menores (1927) estabeleceu diretrizes claras para o trato deste público, regulamentando a delinquência, liberdade vigiada, trabalho infantil, tutela e pátrio poder. Deu autoridade a figura do juiz que, além de total poder de intervir no abandono físico e moral destes, poderia retirar o pátrio poder dos pais, interná-los, repreender, constituir a liberdade vigiada etc. O destino de meninos e meninas pobres estava à mercê do julgamento e da ética destes, que se valendo de uma justiça repressiva e moralista, prescrevia as formas de tratamento dos chamados menores. A assistência aos meninos e meninas pobres é objeto de atenção e de controle do Estado, regulamenta-se a proteção (mais da sociedade do que destes), iniciando um debate que, no discurso, priorizava a educação em detrimento da punição, já institucionalizada. Classifica-se e institucionaliza-se a diferença entre "menores", entenda-se pobres, de crianças e adolescentes que faziam parte da cadeia produtiva ${ }^{19}$.

No interior das políticas populistas do Governo Vargas, na primeira metade do século XX, na tentativa de formulação de sistemas de assistências para atender o público em condições de pobreza e miséria, especialmente os menores, o governo cria o Departamento Nacional da Criança (DNC), o Serviço de Assistência ao Menor (SAM) e a Legião Brasileira de Assistência $(\mathrm{LBA})^{20}$. O SAM, órgão ligado ao Ministério da Justiça, de orientação correcional e repressiva, era semelhante a um sistema penitenciário para a população de menores. As instituições, em formato de internatos, reformatórios e casas de correção, eram arquitetadas e pensadas em divisões de acordo com a tendên- 
cia ou predeterminação dos meninos: autor de ato infracional, delinquente em potencial, situação irregular, menor carente e abandonado e outros. Devido ao seu caráter repressivo e ineficaz, este órgão atuava sob críticas, juntamente com outras práticas sustentadas pelo Código do Menor ${ }^{21}$. Nos anos 60, as autoridades responsáveis por este público, como juízes, legistas e outros, se dividiram em dois grupos, os que defendiam políticas públicas para o menor como sujeito de direitos e os que defendiam a manutenção da política repressiva, que tinha o menor como objeto do direito penal.

Caracterizado pela Doutrina de Segurança Nacional, o período do regime militar (1964-1985) foi marcado pela Política Nacional do Bem-Estar do Menor que criou em rede nacional a Fundação Nacional do Bem-Estar do Menor (FUNABEM-1970) e pelo Código de Menores (1979), que interferia e decidia a vida dos meninos e meninas no interior de uma política repressiva para toda a população. A FUNABEM, a despeito de ser criada para substituir o SAM, herdou não somente os espaços físicos, mas também pessoas e histórias. A intenção era dar assistência, sob a égide da internação, aos meninos e meninas abandonados, carentes, infratores e outras proposições que caracterizavam mais fortemente o chamado menor. Já o Código de Menores, apesar de propor uma revisão do CM de 1927, manteve seu aspecto fundamental baseado na arbitrariedade, assistencialismo e repressão, efetivando o conceito de "menor em situação irregular"22. As autoridades judiciárias desarticularam o movimento que propunha um atendimento menos repressivo e, com seus poderes extensos, estabeleceram critérios para definir os meninos e meninas considerados "perigosos", separando-os de outros, reservando-lhes o tratamento e decidindo seus destinos. A divergência de posturas sobre os direitos dos "menores" retorna nos anos 70, movida principalmente por juristas e legisladores, movidos por debates internacionais sobre direitos infantojuvenis. A promoção de meninos e meninas a sujeitos de direitos toma fôlego e cresce ainda mais nos anos 80 com o fim do regime militar e o processo de redemocratização. Os movimentos sociais ligados à criança e adolescente foram decisivos, materializando na Constituição de 1988, no artigo 227, que introduz conteúdo e enfoque próprios da Doutrina de Proteção Integral da Organização das Nações Unidas, trazendo os avanços da normativa internacional para a população infantojuvenil brasileira.

Como é possível perceber nessas rápidas páginas, as políticas sociais para infância e adolescência no Brasil foram marcadas pelas tensões e conflitos inerentes da história. A princípio era a religião que conformava as práticas e definiam os lugares para essa população. No interior do caráter higienista, 
parte da população também assumiu o papel de regenerar os desviantes pobres. Porém, o Estado, desde o século XIX, teve um papel fundamental na regulamentação das políticas sociais voltadas para a infância e adolescência brasileira. Como foi ressaltado, a história não é linear e, as mudanças ocorrem lentamente, sobretudo, inspiradas em experiências anteriores. Ou seja, nada é original. Certamente que na questão que estamos debatendo há mudanças significativas, tanto de ordem legal, como de ordem prática. Contudo, não é possível ignorar que são mudanças baseadas em experiências anteriores e por isso mesmo, muito do que pensamos a respeito dos lugares apropriados para meninos e meninas pobres é fruto da história que registramos, seja de forma intencional ou não.

Também é importante perceber que o sujeito não é separado da sua história, seu desenvolvimento está entrelaçado as suas condições de vida, suas relações sociais e seu universo simbólico. Produto e produtor de história, o homem carrega os traços do seu lugar na sociedade e fala a partir deste lugar. Por isso mesmo, não se pode pretender compreender o comportamento do adolescente em conflito com a lei sem a compreensão de que, historicamente, este fala de um lugar social de exclusão e violência.

O LUGAR DO ADOLESCENTE INFRATOR

E O DESENVOLVIMENTO DE SUA PERSONALIDADE

Lidia llínichna Bozhovich (1908-1981) trabalhou com Vigotski, na Rússia, até seus últimos dias de vida e desenvolveu uma psicologia da personalidade baseada na periodização do desenvolvimento humano, abrangendo motivação e emoção, desde a infância, passando pela adolescência, até a idade adulta. Essa autora estuda as particularidades psicológicas individuais de cada etapa do desenvolvimento que estão diretamente relacionadas com as condições de vida, com o lugar que o sujeito ocupa nas relações sociais e com sua atividade.

Para explicar a relação que a cultura tem com o desenvolvimento da personalidade, Bozhovich (1976, p. 115) analisa o conceito de "situação social do desenvolvimento", apresentado por Vigotski em uma conferência ministrada a estudantes de Medicina da Universidade de Moscou, em 1934. A autora explica que não há idade exata para estipular estágios do desenvolvimento, mas pode-se falar de características gerais de cada etapa. Assim, explica que, para entender o papel do contexto social no desenvolvimento 
do ser humano, é necessário enfocá-lo, não de uma maneira absoluta, mas de uma maneira relativa. Dessa forma, Vigotski dizia que se havia de estudar o meio não como uma "situação social do desenvolvimento", que, pela força contida nesta situação, determina por si só o desenvolvimento, mas que essas influências do meio dependem também das propriedades psicológicas do indivíduo formadas anteriormente. Vigotski considerava esta posição, não só para explicar o surgimento de peculiaridades individuais no desenvolvimento de cada pessoa, mas também para o descobrimento de peculiaridades de cada etapa. Isso significa que não se verificam modificações em aspectos isolados da personalidade, mas, ao contrário, modifica-se a estrutura interna da personalidade como um todo.

Desta forma, Vigotski, na interpretação de Bozhovich (1976), fundamentou a idéia de que, em cada etapa do desenvolvimento psíquico, não atuam somente peculiaridades das funções e processos psíquicos isolados, mas também uma combinação particular. Por outras palavras, no trânsito de uma etapa para outra, crescem e se modificam qualitativamente não só funções psíquicas como, aquisições cognitivas, pensamento e raciocínio lógico, mas também as correlações que estas funções têm entre si. Segundo ele, as diferentes funções psíquicas crescem e se desenvolvem irregularmente. É como se todas as outras funções atuassem no crescimento de uma determinada função específica, numa combinação particular, dentro e por meio dela. Esse processo condiciona a peculiaridade da estrutura da consciência em cada etapa do seu desenvolvimento.

Qualquer elemento do meio, dizia, influência a criança de forma distinta, dependendo da etapa do desenvolvimento em que ela se encontre. [...] incluindo os casos em que as influências do meio sejam invariáveis por seu conteúdo objetivo, influenciam a criança de forma distinta, devido às transformações que acontecem com a própria criança. (VIGOTSKI, 1934 apud BOZHOVICH, 1976, p. 122, tradução nossa)

Assim, para se entender a influência do meio na formação das particularidades psicológicas do indivíduo segundo sua idade, é necessário levar em conta, não somente as transformações ocorridas no meio, mas também as mudanças ocorridas na própria pessoa que, por sua vez, condicionam o caráter da influência do meio sobre seu desenvolvimento psíquico posterior. Neste contexto, Vigotski definiu o conceito de "situação social do desenvolvimento" como sendo: 
Aquela combinação especial dos processos internos de desenvolvimento e das condições externas, que é típica em cada etapa e que condiciona também a dinâmica do desenvolvimento psíquico durante o correspondente período evolutivo e as novas formações psicológicas, qualitativamente peculiares, que surgem no final de cada período. (VIGOTSKI, 1934 apud BOZHOVICH, 1976, p. 123, tradução nossa).

A partir daí, Bozhovich (1976) trabalha o conceito de vivência, entendendo-a como sendo a relação afetiva do indivíduo com o meio. Vigotski não aprofundou seus estudos sobre as vivências, mas, segundo ele, para se analisar como o contexto histórico interfere no desenvolvimento e como determina seu curso, é necessário compreender também o caráter das vivências do indivíduo, ou seja, o caráter da relação afetiva que esse estabelece com o meio. Ao falar de estado afetivo, Vigotski tem em conta não só uma emoção intensa, provocada por uma influência externa muito forte, mas também, vivências emocionais prolongadas e profundas.

Bozhovich (1976) acrescenta que o caráter das vivências define o caráter e o estado das necessidades presentes no sujeito e, evidentemente, quanto mais essenciais sejam as necessidades, mais fortes e profundas são as vivências. Por outras palavras, atrás das vivências estão o mundo das necessidades do indivíduo, suas aspirações, seus desejos e propósitos, em seu complexo entrelaçamento e em sua correlação com as possibilidades de satisfação destes desejos.

E todo este complexo sistemas de vínculos, todo este mundo de necessidades e aspirações da criança deve ser decifrado para poder compreender o caráter da influência das condições externas sobre o desenvolvimento psíquico da criança (BOZHOVICH, 1976, p. 128, tradução nossa).

Resumindo, diríamos que o caráter das vivências dependerá, em primeiro lugar, das necessidades ou de uma combinação de necessidades que esta vivência reflete; em segundo lugar, do grau de satisfação destas necessidades. Desta forma,

Pelo caráter das vivências, pode-se julgar acerca da estrutura da esfera motivacional da criança e, pelo contrário, conhecendo as necessidades e aspirações da criança, assim como as possibilidades de sua satisfação, pode-se predizer, com grande probabilidade, o caráter de suas vivências (BOZHOVICH, 1976, p. 129, tradução nossa). 
Então, na opinião da autora, a vivência reflete o estado de satisfação do sujeito em suas relações com o contexto social. Dito de outra forma, partindo das vivências, podemos desvendar a complexidade das condições internas e externas que determinam a formação da personalidade humana. Assim, a vivência cumpre uma função extremamente importante que é a de informar o caráter da relação que o sujeito está estabelecendo com o meio e de orientar sua conduta. Ou seja, as vivências, definidas e estabelecidas pelo ambiente são essenciais ao bem-estar emocional do sujeito. A influência que essas vivências exercem são quase sempre não conscientes, mas se tornam essenciais para a formação das representações conscientes do sujeito.

Na primeira infância, as relações sociais têm repercussões emocionais sobre a criança que podem ser altamente destrutivas, pois, essa não tem completa consciência nem tampouco possui um rol de significações em relação a essas vivências. Isto é, a criança possui poucos recursos para reestruturar o sentido psicológico dos impactos emocionais que podem deixar marcas em etapas posteriores. Já as crianças maiores, que permanecem na escola por longos espaços de tempo, ocupam-se de atividades em comum - o estudo, a construção e apropriação de um conhecimento socialmente acumulado e valorizado pela cultura - que conduzem ao surgimento de novas relações interpessoais: o desejo de estar junto com os colegas, de fazer julgamentos entre si, de cumprir tarefas solicitadas, de trabalhar. Surgem assim, interesses pela opinião dos companheiros, além de aquisições e construções coletivas.

Em outras palavras, na educação formal, durante a idade escolar pequena, são construídas relações coletivas que no fim desse período podem gerar no adolescente, aspirações, necessidades e motivos para ocupar um lugar na vida social de seu grupo. Esse caráter das relações interpessoais passa para novas esferas de vida do adolescente. Suas preocupações e interesses partem, agora, dos companheiros e não existe mais uma condição de maior dependência do adulto. E são precisamente essas novas relações que constituem a condição que determina as necessidades e tendências afetivas de sua personalidade. Assim, deixar uma grande parte de crianças longe da escola, numa sociedade escolarizada como a nossa, pode gerar no adolescente uma falta de motivos reguladores de sua conduta na direção da escolarização, da construção do conhecimento e de uma vida laboral independente e construtiva. Nesse momento, educadores e sociedade, com poder de polícia, tendem a tomar atitudes disciplinares severas que, ao contrário, só conduzem a uma maior oposição dos adolescentes à escola e às regras sociais. 
Quando relacionamos o conceito de situação social do desenvolvimento com os adolescentes infratores, frisamos a importância das vivências, inclusive nos centros de internação, na formação da personalidade desses adolescentes, pois todo esse complexo sistema de vínculos, esse mundo de necessidades e aspirações deve ser, até certo ponto, compreendido e gratificado nas relações que ele estabelece com o outro no seu processo de individuação. Ou seja, é necessário compreender o caráter da relação afetiva, suas necessidades, bem como os recursos psicológicos do adolescente para reestruturar suas próprias necessidades e sentidos sobre a vida, sentidos esses que se (re)constituem nas comunicações, nas atividades orientadoras do desenvolvimento nesta etapa e nos novos sentidos subjetivos gerados neste contexto de vivências emocionais que têm uma importância vital para $o$ adolescente.

Artigo recebido em: 16/11/2014 Aprovado para publicação em: 16/12/2014

\section{UNIVERSAL, UNIQUE AND EXCLUDED: THE CONSTRUCTION OF THE POSITION OF IMPOVERISHED ADOLESCENT IN THE BRAZILIAN SOCIETY}

ABSTRACT:This article proposes a reflection about the position collectively constructed and tailored for destitute adolescents in the Brazilian society, through the history of policies and practices of education for Brazilian boys and girls, from the Portuguese colonization to the Statute of the Child and Adolescent. The text resumes the concept of "social situation of development" in order to realize that the subjects are not separated from their history, and their development is interweaved with their living conditions, social relations and symbolic universe. As a product and producer of history, man carries the traces of his position in society and speaks from this position. Therefore, we cannot pretend to understand the behavior of youth offenders or want to educate them, without understanding that, historically, they speak from a social position of exclusion and violence.

KEYWORDS: Impoverished adolescent. Social exclusion. Education's role. 
UNIVERSAL, SINGULAR Y EXCLUIDO:

\section{LA CONSTRUCCIÓN DEL LUGAR DEL ADOLESCENTE EN LA SOCIEDAD BRASILEÑA}

RESUMEN: El texto propone una reflexión sobre el lugar colectivamente construido y destinado a los adolescentes pobres en la sociedad brasileña, por medio de la historia de políticas y prácticas de educación para los niños y niñas del Brasil desde la colonización portuguesa hasta el Estatuto da Criança e do Adolescente y retoma el concepto de la situación social del desarrollo con el fin de percibir que el sujeto no es separado de su historia, su desarrollo está entrelazado a sus condiciones de vida, sus relaciones sociales y su universo simbólico. Producto y productor de la historia, el hombre carga los rasgos de su lugar en la sociedad y habla a partir de este mismo lugar. Por eso, no se puede pretender comprender el comportamiento del adolescente en conflicto con la ley o pretender educarlo sin la comprensión de que, históricamente, éste habla desde un lugar social de exclusión y violencia.

PalABRAS CLAVE: Adolescente pobre. Exclusión social. Lugar de la educación.

\section{NOTAS}

1) Ao organizarem a obra História dos jovens, Levi e Schimtt (1996) salientaram que escrever essa história implicava em uma multiplicidade de perspectivas, iniciando pela culminância da fase da socialização que precede a vida adulta, como também ao processo de socialização dos indivíduos entre a infância e a idade adulta.

2) Nosso recorte neste texto é a adolescência, não trataremos de infância. Contudo, em certos tempos históricos isso não é fácil separar, visto que os papéis não eram tratados de forma rígida e específica.

3) No Diccionario da Lingua Brasileira de 1832 (SILVA PINTO, 1832), por exemplo, encontramos a idade de 14 até os 25 anos definindo o verbete Adolescencia (grafia da época) e a mesma idade definindo Mocidade e Moço. As incertezas que caracterizam a concepção são inerentes aos processos históricos, assim como os termos recorridos para caracterizar o que identificamos como adolescentes hoje. Tratados da Antiguidade, manuais higiênicos, literatura religiosa e outros documentos históricos seguem uma perspectiva semelhante ao dicionário oitocentista.

4) Por exemplo: Ocidente/Oriente; Antiguidade, Idade Média, Moderna e Contemporânea e muitos outros parâmetros de estilos, muitas vezes, incomparáveis.

5) Estas, nem sempre eram órfãs e sim pobres, prostitutas, judias, infiéis etc. Ana Miranda em sua obra Desmundo (1996), narra a viagem forçada de meninas no século XVI que eram trazidas de Portugal para o Brasil com o objetivo de se tornarem esposas dos portugueses residentes na Colônia portuguesa. O livro, que virou filme 
com o mesmo nome, mostra a relação que mesmo para a época, é construída sob forma violenta, pois distante de seu país, as meninas eram submetidas a todo tipo de maus tratos.

6) Designação tupi estendida para crianças e rapazes novos.

7) Vale anotar que a educação baseada no temor, vigilância, punição e sujeição não era estranha ao período, tanto para os meninos indígenas como para outros meninos e meninas.

8) Entre eles o nomadismo, que interrompia a continuidade da formação dos meninos.

9) Ver mais sobre isso em Chambouleyron (1999).

10) Devido a preocupações que permeavam a sociedade cristã da época, reservava-se mais instituições e atenções às meninas desvalidas, consideradas do sexo frágil. Se não fossem contidas por uma educação adequada, estariam expostas ao perigo de uma vida devassa, escandalosa, indecente etc. Com disciplina rigorosa, as instituições femininas, além de impor a educação moral e religiosa, ensinavam algumas práticas destinadas às meninas de elite, como línguas, música, piano etc., visando ao mundo do trabalho de serviçais domésticas prestativas, dóceis e disciplinadas.

11) Ver mais em Venâncio (2000).

12) Além de ministrar a doutrina cristã, leitura, escrita e aritmética.

13) A pobreza, na contramão da sonhada modernidade, aumentava e ameaçava a estabilidade da ordem pública, perturbando o sossego das pessoas "de bem". Nas ruas das cidades que cresciam de forma vertiginosa, acompanhada da explosão demográfica, sob ares da modernidade, que contrastava com os conflitos urbanos de diferentes espécies. As tensões sociais, provocadas pelo crescimento desordenado das cidades, a falta de estrutura, de emprego, moradia, escola etc. proporcionou o aumento do índice de criminalidade e os mecanismos de repressão governamental, representada pela polícia. O índice de criminalidade crescia junto com a vigília e a repressão, motes que guiavam os aparelhos governamentais nas grandes cidades.

14) Os dois olhares para a população se definiam pela classe social: os futuros da pátria, estavam nas escolas estudando; o outro olhar, o que preocupava, estava nas ruas, o menino na rua que começava a ser constituído, produzido, como menor de rua.

15) Diferente do Código Penal do Império, que prescrevia punição em casas de correção para meninos de nove a quatorze anos que, com "discernimento" cometiam crimes, o Código republicano previa a punição em estabelecimentos disciplinares industriais. A despeito de a legislação indicar os locais para disciplinar os menores, essas instituições, junto com as religiosas, se recusavam a receber os menores fichados pela polícia. 
16) Como a prioridade não era o ensino, mas sim formar para o trabalho, os internos saiam semianalfabetos, além de a disciplina rígida, o isolamento e as punições ocasionavam fugas constantes, muitas vezes coletivas.

17) Rotulados também de incorrigíveis, delinquentes, difíceis, anormais, problemáticos e outros.

18) Após a primeira Grande Guerra aprovou-se a Declaração dos Direitos da Criança (1921) e, no Brasil, o Código de Menores (1927), que proibia o trabalho de crianças até 12 anos, definia a imputabilidade penal até os quatorze, sendo que até os 18 anos seriam punidos pelos crimes em estabelecimentos especiais.

19) Ver mais em Santos (2000); Faleiros (1995); Passone (2007).

20) A Legião Brasileira de Assistência (LBA), entidade federal, caracterizada pela prática assistencialista, que visava à formação para o trabalho, ligada à figura da primeira dama se chamava originalmente Legião de Caridade. No decorrer das décadas expandiu seu atendimento por meio de casas que atendiam pequenos trabalhadores urbanos e rurais, por meio de apoio assistencial, socioeducativo, aprendizagem, capacitação e encaminhamento de crianças e adolescentes pobres ao trabalho, além de programa de apoio a meninas que apresentavam problemas de conduta.

21) As instituições eram cognominadas de "universidade do crime", pois, os internos, como em uma penitenciária de adultos, eram misturados, possibilitando pessoas a aprenderem umas com as outras. Assim, um menino que fugiu de casa, era posto junto com outros que já detinham experiências nas ruas, por isso o local era considerado ineficaz e perigoso.

22) Não obstante o regime militar contraiu formalmente as ações da Declaração Universal dos Direitos da Criança, contraditoriamente instituía um novo código de menores, ainda mais repressivo que o anterior.

\section{REFERÊNCIAS}

BOZHOVICH, L. I. La Personalidad y su Formación en la Edad Infantil. Havana: Pueblo y Educación, 1976.

BRASIL. Estatuto da Criança e do Adolescente. Lei Federal n 8069, de 13 de julho de 1990.

BRASIL. Código de Menores. Lei Federal n 6.697, de 10 de outubro de 1979.

CHAMBOULEYRON, R. Jesuítas e as crianças no Brasil quinhentista. In: DEL PRIORE, M. (Org.). História das crianças no Brasil. São Paulo: Contexto, 2004. p. 55-83.

FALEIROS, V. P. Infância e processo político no Brasil. In: PILOTTI, F.; RIZZINI, I. (Org.). A Arte de governar crianças: a história das políticas sociais, da legislação e da assis- 
tência à infância no Brasil. Rio de Janeiro: Instituto Interamericano Del Niño, 1995. p. 49-98.

GOES, J. R.; FLORENTINO, M. Crianças Escravas, Crianças dos Escravos. In: DEL PRIORE, M. (Org.). História das Crianças no Brasil. São Paulo: Contexto, 1999. p. 177-191.

LEVI, G.; SCHMITT, J-C. (Org.). História dos jovens: da Antiguidade à era moderna. São Paulo: Companhia das letras, 1996.

MIRANDA, A. Desmundo. São Paulo: Companhia das Letras, 1996.

PASSONE, E. F. Políticas sociais de atendimento à infância e juventude: o caso da Fundação Abrinq. Dissertação (Mestrado em Educação), Programa de Pós-Graduação em Educação - Universidade Estadual de Campinas (Unicamp), Campinas-SP, 2007.

PILOTTI, F. Crise e perspectivas da assistência à infância na América Latina. In: PILOTTI, F.; RIZZINI, I. (Org.). A Arte de governar crianças: a história das políticas sociais, da legislação e da assistência à infância no Brasil. Rio de Janeiro: Instituto Interamericano Del Niño, 1995. p. 12-45.

RIZZINI, I. A Criança e a lei no Brasil: revisitando a história (1822-2000). Rio de Janeiro: Unicef, Cespi/USU, 2000.

SANTOS, M. F. Com a palavra o adolescente: Ressignificando trajetórias de risco em um espaço institucional. Uma experiência em educação para a saúde. Dissertação (Mestrado em Saúde coletiva), Instituto de Saúde Coletiva, Universidade Federal da Bahia (UFBA), Salvador-BA, 2000.

SILVA PINTO, L. M. da. Diccionario da Lingua Brasileira. Ouro Preto: Typographia de Silva, 1832.

VENÂNCIO, R. P. Famílias abandonadas: assistência à criança de camadas populares no Rio de Janeiro e em Salvador - séculos XVIII e XIX. Campinas: Papirus, 1999.

Marilúcia Pereira do LAGO: doutora em psicologia clínica e psicopatologia pela Université de Nice Sophia Antipolis - França. Professora do curso de Psicologia da Universidade Federal de Goiás. Formação em psicanálise e psicopatologia fundamental. Supervisiona estágio em psicologia forense, coordena projetos de formação e desenvolve pesquisas sobre violência e comportamentos aditivos.

E-mail:marilucialago@hotmail.com 
Geisa Nunes de Souza Mozzer: doutora em Psicologia pela Universidade de Brasília $\left(U_{n} B\right)$. Mestra em Psicologia da Educação pela Pontifícia Universidade Católica de São Paulo (PUC/SP). Graduada em Pedagogia pela Universidade Federal de Viçosa (UFV). Atualmente é professora adjunta da Universidade Federal de Goiás (UFG). Pesquisadora do Núcleo de Estudos e Pesquisas em Psicologia, Educação e Cultura (NEPPEC/FE). Coordenadora do Núcleo de Estudos e Coordenação de Ações para a Saúde do Adolescente - NECASAV CEPEA.

E-mail: mozzergeisa@gmail.com

DIANE VALDEZ: doutora em História da Educação (Unicamp), mestra em História (UFG), graduada em História (UCDB). Professora adjunta da Faculdade de Educação da UFG na Graduação e na Pós-Graduação (PPGE/FE). Pesquisadora na área de História da Educação do Núcleo de Estudos, Pesquisa e Documentação Educação, Sociedade e Cultura (NEDESC). Militante do Movimento de Meninos de Rua/GO.

E-mail:divaldez@ufg.br 